\title{
Achieving Proficiencies In Economics Capstone Courses
}

Michael C. Seeborg, (Email: mseeborg@iwu.edu), Illinois Wesleyan University

\begin{abstract}
This paper argues that capstone courses in economics should be integrative experiences that require students to demonstrate six core proficiencies. The capstone economics senior seminar at Illinois Wesleyan University is used as an example of how a capstone course that requires completion of an original research paper might achieve these proficiencies. Also, carefully designed co-curricular activities, such as student-edited undergraduate journals, and participation in undergraduate research conferences are recommended as complements to capstone research courses.
\end{abstract}

Keywords: Undergraduate curriculum, capstone courses, undergraduate research, teaching pedagogy.

\section{INTRODUCTION}

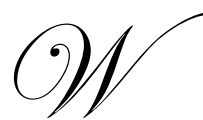

hile capstone courses are becoming common in undergraduate economics programs, they vary greatly in content and sometimes are not required for all majors. It is argued here that it might be desirable to design a capstone course that culminates in an original empirical research project and focuses on helping students to achieve specific proficiencies. Using the economics senior seminar course at Illinois Wesleyan University as an example, this paper explores some pedagogical approaches to increasing the quality of undergraduate research within the capstone course by structuring research assignments so that students can achieve a meaningful integrative experience that allows them to develop and demonstrate the six proficiencies that Hansen (2001) believes should be the goal of undergraduate economics programs. It also reports on our attempts to use undergraduate publication and conference presentations to provide incentives for students to do quality research.

Incentives to do good undergraduate research can be built directly into the course design and can be engineered into co-curricular activities, especially undergraduate conferences and journals. Given the increased emphasis on capstone experiences and honors courses in economics programs, there is surprisingly little growth in co-curricular activities that emphasize undergraduate research. Undergraduate journals are found in only a few economics programs, and undergraduates seldom present their research at conferences.

\section{BACKGROUND}

The importance of research and writing has been the focus of considerable attention in the economics literature over the past couple of decades. Many economics departments have responded by developing capstone courses and/or honors programs (Siegfried 2001). These changes are consistent with the advice of a group of scholars who have advocated such "deepening" of economics curriculum (Hansen 1986, 1998, and 2001; Siegfried 2001; and Siegfried, et. al., 1991).

Hansen (1986; 2001) has long argued that we need to help students develop a set of proficiencies. These proficiencies cannot all be achieved through traditional classes that emphasize only lecture and exams. The six proficiencies discussed by Hansen (2001) are:

1. Access existing knowledge

2. Display command of existing knowledge 
3. Interpret existing knowledge

4. Interpret and manipulate economic data

5. Apply existing knowledge

6. Create new knowledge

These proficiencies are ranked in order of cognitive requirements, with proficiency 6 generally being reached in a capstone experience involving research and at least one paper. For many students, completion of a well designed capstone experience could demonstrate all six proficiencies. Hansen (2001) emphasizes the importance of helping students develop these proficiencies throughout the economics curriculum with pedagogical approaches that involve active learning such as those advocated by Saunders and Walstad (1998). Hansen (1998) advocates integrating writing assignments throughout the entire undergraduate economics program, maintaining that student writing can help professors to assess what students are really learning. In addition, frequent writing within the economics curriculum could help students learn content while adding excitement to both teaching and learning.

Depth within the curriculum is usually achieved through course sequencing, prerequisites and through a capstone experience (Siegfried, et. al. 2001). Many programs in economics now require some sort of integrative capstone experience, at least for the best students. Siegfried, et. al., (1991) summarizes the argument for depth succinctly:

To complete the process of intellectual maturation, every student should be required to apply what he or she has learned to an economic problem and, in the process, acquire experience really "doing economics." For a particular intellectual encounter to accomplish this goal, it should involve considerable responsibility on the student's part for formulating questions, gathering information, structuring and analyzing information, and drawing and communicating conclusions to others in an oral and/or written form. The depth requirement should be implemented in each elective course and complemented through the establishment of "capstone experiences" such as special seminars or traditional opportunities for senior theses, honors research projects, and independent studies. (Siegfried, et. al., 2001, p. 218) (author's emphasis)

Co-curricular activities that provide incentives for students to do quality research could be good complements to undergraduate economics programs that stress writing. Presenting research at academic conferences, submitting articles for peer review, and participating as editors for undergraduate journals are three of the most important activities.

The importance of linking active learning to co-curricular activities has received scant attention in the literature. However, Carlson, et., al. (1998) argue that peer reviewed undergraduate journals can help improve undergraduate writing in economics. They argue that students benefit in the same way as academic economists do from the peer review process. Bringing peer pressure into the process encourages students to do their best work, and peer evaluation may give students useful evaluation that may complement evaluation from instructors. Students, like their professor mentors, respond with higher quality work when they know that they are writing for a much larger audience than a single professor. Also, student editors learn leadership and teamwork skills as they work on journals, and they expand their knowledge base as they review articles written from different perspectives. (Carlson, et. al., 1998, p. 81).

The remainder of this paper describes efforts at Illinois Wesleyan University (IWU) to develop senior proficiencies in economics through a set of capstone experiences. Section III describes the IWU senior seminar course that guides students through an original research project by breaking projects into manageable components and requiring students to do multiple drafts of their work and obtain feedback from peers and faculty members. Section IV focuses on how the IWU economics department uses outcome oriented co-curricular activities, such as student edited journals and undergraduate research conferences, to provide external incentives for good undergraduate research. 


\section{RESEARCH ORIENTED SENIOR SEMINAR COURSE}

The senior seminar course at Illinois Wesleyan University, called Senior Project, is a required capstone course for all senior economics majors. It is an integrative experience that requires students to apply what they have already learned to review literature, apply basic theory, test hypotheses using empirical models, and write multiple drafts. Ideally, the senior seminar should help students demonstrate all six of Hansen's proficiencies: accessing knowledge; displaying command of existing knowledge; interpreting existing knowledge; interpreting and manipulating data; applying existing knowledge; and creating new knowledge (2001).

\section{A. Positioning The Senior Seminar Course Within The Major}

The success of any capstone course in developing proficiencies requires an overall economics curriculum that prepares students for original research. Capstone courses will probably be less effective if the major program lacks depth. Depth is achieved, in part, with prerequisites. Unfortunately, many economics programs, especially at smaller universities, must limit the number of prerequisites for upper division economics courses because of the need to serve general education and business students in addition to economics majors.

Depth is also achieved by requiring writing assignments in most courses. Well crafted writing assignments, especially those that require students to revise and resubmit graded drafts, can help to develop critical thinking and organizational skills that prepare students for capstone courses.

At Illinois Wesleyan University, as is the case at many universities, we are not able to require intermediate theory for very many of our upper division economics elective courses because of the needs of non majors. However, we do require papers and nearly all of our courses and we try to sequence courses for majors in a way that prepares them to do original research. The ideal sequence starts with elementary economics which is followed by statistics and the two intermediate theory courses. Ideally, the intermediate theory courses are followed by econometrics, which has prerequisites of statistics and intermediate microeconomics. In econometrics, students apply statistical models to an original research question. They test hypotheses using econometric methods, write a paper and present it to the class. Although econometrics is not a required course for majors, it is highly recommended and most students take it, in part because it is great preparation for their senior research experience. During the fall of the senior year economics majors are required to take the senior seminar course (Senior Project), which is followed in the spring with the optional Advanced Research Seminar.

About one-half of the students that complete an original economics project in the senior seminar course choose to continue their research through the spring in a seminar on advanced research. Many students in the advanced research seminar also participate in the university-wide honors research program where they work with four member faculty committees. An advantage of offering the capstone course during the fall rather than the spring is that students with a strong interests and aptitudes for research can then work on their research projects for an entire academic year.

\section{B. Creating Senior Seminar Content To Develop Proficiencies}

An effective senior seminar capstone experience allows students to demonstrate Hansen's six proficiencies. Although the first three proficiencies should already be developed to some extent, the senior seminar gives students the chance to further develop these basic proficiencies.

The first proficiency is to learn to access current knowledge. Early in the semester students work with a library faculty member to improve their ability to access literature and data sets that are related to their research question. Tying library instruction to students' research topics provides a strong incentive for them to internalize and apply search techniques early in their research.

The second proficiency is to display a command of existing knowledge and the third to interpret existing knowledge. The senior seminar has a set of assignments that require students to summarize and interpret project 
related literature. For example, students do an annotated bibliography that includes a summary of those parts of articles and books that relate to their own research topic and a brief description of how that literature relates to their own research project. They also find and critique a number of published books and articles that relate to their paper. Critiques of empirical papers are usually two or three pages long and address a set of standard questions (see Appendix A ).

The idea behind the guided critique is to get students to think about the research process from a researcher's perspective. They are expected to identify the connections between research problem, theoretical framework, empirical model and results? For example, they must think about how the paper's conceptual framework (i.e., theory) is connected to the research problem and also how the conceptual framework is used to generate testable hypotheses. They also must think about whether the empirical model provides an appropriate test of the research hypotheses. Finally, they must evaluate how the results of the empirical analysis address the original research question. Requiring students to evaluate related literature with a focus on the research process helps them think about and develop their own research project. It also helps them to further develop Hansen's second and third proficiencies, namely showing a command of existing knowledge and interpreting existing knowledge (Hansen, 2001).

Students also critique senior honors projects authored by former Illinois Wesleyan students. Critiquing student work is an activity that they enjoy very much. Also, the real possibility that their own work might be subject to criticism in future years is a powerful incentive for them to do good work.

The capstone course should also try to develop Hansen's higher level proficiencies. His fourth proficiency requires students to interpret and manipulate economic data. This is achieved in the senior seminar by requiring students to access an appropriate data base and to use econometrics or statistical techniques to test hypotheses. The results of the hypothesis testing are presented and interpreted in the final sections of the paper.

The fifth proficiency requires students to apply existing knowledge. The key is that students become familiar with the literature on their topic and connect every portion of their project to the literature. We find that students will often adopt conceptual frameworks from the literature (e.g., basic supply and demand, human capital theory, growth theory). They also often will use econometric techniques (e.g., regression, probit) that are common in the literature.

Hansen's sixth proficiency is perhaps the most challenging for undergraduates since it requires them to create new knowledge. We require that each project make some sort of original contribution. While most senior projects would not be considered groundbreaking work, they almost all create new knowledge. Some students find unique data sets to test hypotheses. Others find new explanatory variables. Occasionally, they develop unique conceptual frameworks and empirical models. We require that senior projects have original components, and do not permit simple replication of past research. Undergraduates can make original contributions and most appreciate the opportunity to do this in the capstone senior seminar course.

\section{Organization Of The Seminar}

The seminar is based on many graded assignments that culminate in an original research paper. During the semester, several drafts of various sections of the papers are graded and returned with written suggestions for revision. Peer reviews are also part of the process and students spend a significant amount of class time in small group discussion of their projects. All students make a formal presentation of the final project to the seminar class at the end of the fall semester and many choose to continue working on their projects through the spring semester, often working with individual faculty members or research honors committees.

In general, the seminar consists of two parts. The first part is designed to help students identify their research topics and guide them through a number of small graded projects. These include: a three page review of a survey article on the topic area (20 points); a two page critique of an IWU economics honors project (20 points); a two page critique of a paper that has theory related to their project ( 20 points); a two page review of a theory paper 
that's related to their topic (20 points); a two page critique of a related empirical paper (20 points); an annotated bibliography that relates the annotated article to their own project (40 points); a topic proposal (20 points); and a full sentence outline of their research project (40 points). By half way through the semester students should have a good understanding of the literature that relates to their general topic area and they should have a rather detailed outline of their projects. In terms of Hansen's competencies, students spend the first half of the semester working on the first three competencies and planning how they will demonstrate the last three competencies during the second half.

As the second half of the semester begins, students are ready to exercise Hansen's last three levels of competency. They have acquired data and are ready to do original research. The emphasis changes from classroom activities to more one-on-one consultation, small group work, peer review, statistical analysis, and writing drafts.

Revision is emphasized and grades are attached to early drafts so that students take the revision process seriously. There are a total of three drafts graded: the first draft of the first half of the paper (50 points), a draft of the entire senior project (100 points), and the final draft (300 points).

The grading criteria for the final paper are very specific and consist of 24 items which are detailed in Appendix B. The idea is to encourage students to do original research within the conventions of the discipline. For grading purposes, each paper is divided into several areas, and points are assigned to several subcategories within each area. The general areas that are graded are: development of the research problem, treatment of literature, theory, Empirical Research Design, Results, Conclusions, and Style and Grammar.

There are several ways of judging the success of the senior capstone experience. First, the final projects demonstrate proficiencies in economics. The department uses the final evaluation sheet (Appendix B) to help gauge levels of proficiencies of seniors. In fact, averages across all seniors on each of the 24 areas graded become part of the assessment process for the department. A second measure of success of the capstone experience is the number of students who choose to continue their research into the spring semester with faculty mentors or honor's committees. The final quantifiable measure of success is the number of students who present their work at research conferences or submit their papers for publication. Our department believes that providing opportunities for seniors to publish or present their research creates valuable incentives and, at the same time, adds an element of excitement to the research process. Our experience with undergraduate publication and undergraduate research conferences are described in the following two sections.

\section{UNDERGRADUATE JOURNALS AT ILLINOIS WESLEYAN UNIVERSITY}

At present there are not very many opportunities for undergraduate economics majors to publish their research. This is unfortunate since students involved with journal publishing as authors or student editors are working at achieving Hansen's proficiencies.

An academic major program that emphasizes writing and active learning will probably benefit by helping students establish a student edited journal. These journals are not too difficult to establish and when they are web based they are quite inexpensive to establish and maintain. Two models are explored: student edited in-house publications that publish articles written by students at that university and online publications that solicit articles from other universities.

\section{A. Student Edited In-House Publications}

Illinois Wesleyan University's in-house publication, The Park Place Economist (2005), has a student editorial staff that considers articles submitted by IWU students. The editorial staff also writes feature stories about economics alumni and news stories about the department. A hard copy version of the journal is published and distributed to Illinois Wesleyan University students, faculty, and alumni. The journal is also posted online. The Park Place Economist, which has been published for fifteen years, is an excellent tool for encouraging good research and maintaining contact with alumni. It also helps students develop leadership, editorial skills, and Hansen's proficiencies as they participate on the editorial team. 
Students like the idea of an in-house journal because it provides a public outlet for their research. Students, like professional economists, do better work when there is a good chance that their work is appreciated and acknowledged by a wider audience.

There is, however, a significant upfront cost to faculty members during the first couple of years of operation. It is critical that student edited journals have very committed faculty advisors. During the first year, the faculty advisor needs to work hard with the student editorial staff to establish important structures and policies for the journal. These include:

- Organizational structure of the editorial staff

- $\quad$ Timelines, including deadlines for paper submissions, review by student editors, final acceptance (or rejection) by the editorial board, proofreading, and submission of the journal to the printer (or posting online)

- $\quad$ Editorial guidelines for style, content, documentation, page limits, and so on

- $\quad$ Criteria to be used in judging whether or not to select articles for publication.

While it is critical that the faculty advisor be directly involved in this process, it is also important that student editors to have enough involvement in decision making that they have real ownership of the final product. We found that after the first two years, the time commitment of the faculty advisor was much reduced. By then, journal policies had been firmly established and students felt comfortable running the journal with minimal faculty involvement. Over the first couple of years of operation, the faculty advisor's role shifts from "policy maker" to giving advice and information when asked by student editors and providing loose oversight to make sure that the student Editor-in-Chief follows established policies.

Thus, we don't see the faculty advisor as "running" the journal. After the journal is established, the faculty advisor is best characterized as a "consultant" to the students and as an external "auditor." When this happens, the students feel greater ownership over their product. The final journal layout may not look quite the way the faculty advisor would prefer and the articles that students choose to publish may not be the same ones that the faculty advisor would have chosen, but that's alright. Students are in control and they are learning by doing.

In establishing the editorial staff, it is important to have definite lines of authority. The Park Place Economist has an Editor-in-Chief who has final editorial authority and makes sure that deadlines are met. The Technical Editor is responsible for the formatting of the hard copy journal and for organizing the web page for the online version. The Assistant Editor-in-Chief helps the EIC wherever needed. Typically, the EIC is a senior who has worked on the journal for a number of years and the Assistant is a junior who is being groomed to become the next year's EIC. Economics majors are selected for a number of other positions, including Articles Editor, News Editor, and Proofreading Editor. In a typical year, about 25 students work on the journal. Usually, student editors work their way up through the editorial ranks. For example, an economics major might serve as Proofreading Editor as a freshman, as Articles Editor as a sophomore, as Assistant to the Editor-in-Chief as a junior, and as Editor-inChief as a senior.

In-house undergraduate journals are also a great tool for maintaining alumni relations. Of particular interest to alumni were feature stories in the Park Place Economist that were written by the six news editors including:

- $\quad$ An interview with the Department Head

- An interview with an alumnus who is in a $\mathrm{PhD}$ program

- $\quad$ Notes about alumni achievements

- $\quad$ A story about the graduating class

- $\quad$ An article about the new online journal

- $\quad$ An article from an alumna in the Peace Corps

- $\quad$ An article about a faculty member who had just received tenure 
All economics alumni receive a copy of the journal in the mail, and many have commented on how the journal has kept them connected with the department.

A less costly alternative to doing a hard copy in-house journal is to post the journal online. If the online alternative is chosen, a newsletter could be sent to alumni directing them to the address where the journal is posted. This newsletter could be either hard copy or an email.

In sum, the in-house Park Place Economist journal generates many benefits for students:

- It is a meaningful co-curricular activity that allows student editors to develop leadership and teamwork skills

- $\quad$ By allowing students to write for a broader audience, the journal provides an incentive for students to improve their writing and research skills and in the process helps them achieve Hansen's six proficiencies

- It encourages alumni to stay in touch with the department and to interact with current students

\section{B. Student Edited Online Journal: (Undergraduate Economic Review)}

While in-house publications like the Park Place Economist meet many educational objectives, they can not quite replicate what academic economists actually do with their research. For example, in-house publications limit the potential audience and do not give authors the chance to interact with scholars at other institutions through external review.

The recent introduction of internet only publications, such as the journals of the Berkeley Electronic Press, suggests the feasibility of on-line publishing for academics. This technological shift in journal publishing toward web-based formats creates fascinating possibilities for undergraduate journals in economics as well. Creating a journal website is no longer difficult, especially for web savvy students, and the cost to departments is near zero -excluding time costs, of course. Illinois Wesleyan University's first foray into online publishing came through a joint venture with Illinois State University to produce the University Avenue Undergraduate Journal of Economics (2007). The joint venture produced several volumes.

We learned a great deal through this collaboration that led to the decision to eventually create our own online journal, The Undergraduate Economic Review in 2005. From the earlier collaboration, we discovered that student editors learn from considering the economic content, organization, and technical merit of student edited articles. The authors also benefit from the constructive interaction with student editors and from the feedback that they get from faculty members as they prepare their research for possible publication (Carlson, et. al. 1998).

Also, published student articles can be used in classroom assignments as samples of quality undergraduate research. For example, the capstone senior project course students are now assigned to read and critique several articles from The Undergraduate Economic Review. They enjoy critiquing student research for several reasons. First, the work is often interesting to them because it is produced by peers. Second, many undergraduate articles are written at a level of technical proficiency that is understandable to undergraduates. Third, student authored articles often deal with issues that are of interest to other students. (Carlson et. al. 1998).

While the potential benefits to students of an online journal are significant, faculty advisors need to be aware of some significant startup costs, with almost of them being "time" costs. The three most significant startup tasks during the early stages of developing the Undergraduate Economic Review were establishing an organizational structure, soliciting articles, and establishing reasonable criteria for review.

The first startup task is developing an effective organizational structure. Two principles should be followed: the lines of authority should be clear and there should not be much overlap of responsibility between positions. The organizational structure of the Undergraduate Economic Review is shown in Figure 1. Currently the Undergraduate Economic Review has a student Editor-in-Chief who has overall authority over editorial matters. For example, when reviewers make conflicting recommendations, the Editor in Chief makes the final decision. 
The Managing Editor is responsible for the day to day operations of the journal, making sure that submitted articles are allocated to reviewers and reviewed within the time limits. The Managing Editor also makes sure that accepted articles are posted to the journal and that authors are kept informed of the status of their submissions. Our goal is to keep the review process as short as possible and to make sure that articles are posted to the journal as soon as they are accepted. Ideally, not more than a month will pass between the time of submission and the posting of an accepted article, and it is the Managing Editors responsibility to see to it that time guidelines are followed. One exception to this rule is for articles received after April 15 through August. These articles are held over until September and then reviewed promptly for the next issue.

The Technical Editor has authority over the construction and maintenance of the web pages and works with the Editor-in-Chief to make sure that those pages reflect the purposes of the journal. Where there are disagreements over content on the web pages, the Editor-in-Chief has final authority.

Associate Editors review articles and make recommendations to accept or reject. Currently, all associate editors are Illinois Wesleyan University students. However, as mentioned above, we would like to expand the network of associate editors to up to ten other universities, where the Faculty Advisor at each of these universities would appoint an Associate Editor. We anticipate that a spillover effect of having a network of associate editors is that many would choose to submit their own work for publication, thereby helping to solve the solicitation conundrum.

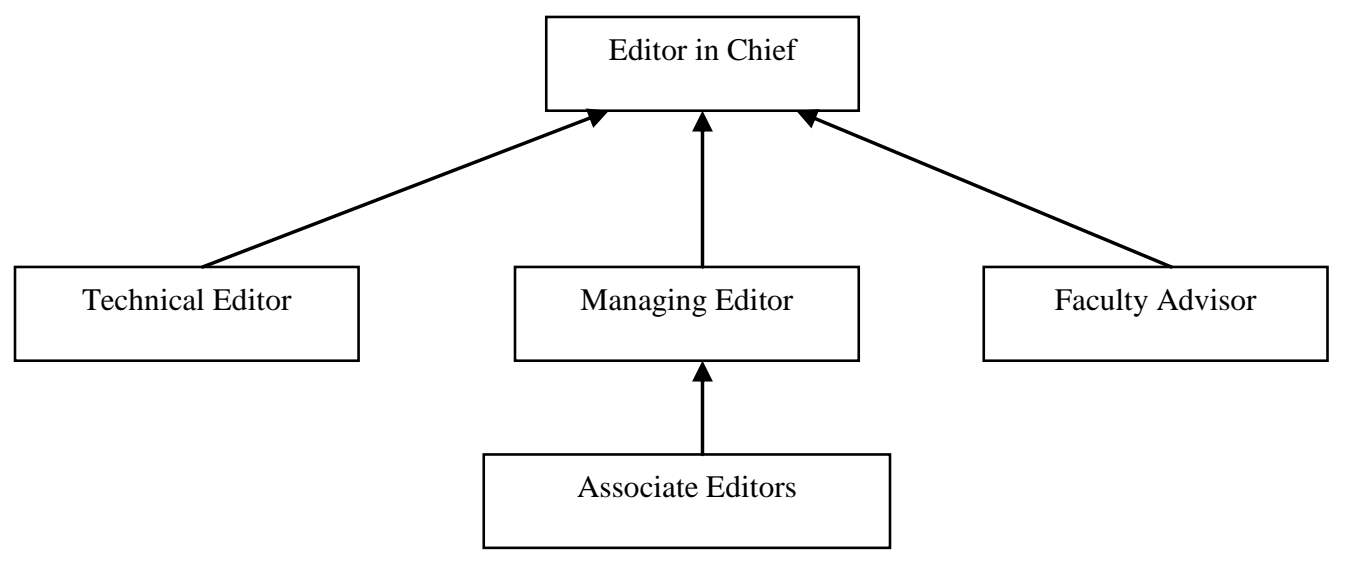

Figure 1: Organizational Structure of the Undergraduate Economic Review

The second difficult startup task is soliciting quality undergraduate papers. Trying to contact students directly is not very effective, and e-mails to department chairs are often overlooked. The fundamental problem is that potential student authors change with every graduation cycle. A solution to this turnover is to work through faculty members from a select set of universities. While students may graduate, we know that most faculty members will be back the next academic year. Also, faculty members who supervise student research tend to do it year after year.

A strategy that The Undergraduate Economic Review is currently pursuing is to partner with a relatively small number of "Faculty Advisors" from about 10 institutions. Ideally, the faculty advisor would teach a capstone type course where research papers are produced. The faculty advisor could then use the possibility of publication as an incentive to encourage students to put extra effort into their research. The faculty advisor would also appoint a student associate editor from among the better students in the program. The Associate Editor would encourage classmates to submit for publication and occasionally review articles. 
Another approach to soliciting articles is used by the undergraduate publication Issues in Political Economy. Each year they sponsor several undergraduate sessions at the annual meetings of the Eastern Economic Association. Students who present articles at professional meetings often have authored good papers and are anxious to submit for possible publication. Undergraduate papers are also presented at the Missouri Valley Economic Association meetings, the Midwest Economic Association meetings, and at the annual Carroll Round international economics conference at Georgetown University.

The third task in setting up an online undergraduate journal is establishing a set of editorial guidelines that are appropriate in assessing undergraduate articles and can be applied by student editors. A set of review criteria were developed in our earlier collaboration with Illinois State University and we have adopted them with only minor modifications. Since undergraduate research takes many forms, developing appropriate criteria is difficult. The criteria must be understandable to student associate editors and must be general enough to apply to a wide range of papers, including empirical papers, conceptual papers, and policy analysis papers. Appendix $\mathrm{C}$ shows the criteria currently being used.

Determining an appropriate publication cycle is also problematic with undergraduate publications. We have decided to have one issue per academic year with continuous posting as articles are accepted. Articles that are received after the April 15 cutoff date will be held through the summer and reviewed when student editors return to campus the following September. The obvious problem with this cycle is that many honors projects and other quality papers are not completed until after the April 15 cutoff. Therefore, these papers could not get the same type of speedy review as papers received before the April 15 deadline. However, we felt that respecting the student editors' vacation schedule was important in maintaining morale. Also, the April 15 cutoff means that each issue can experience closure in late April when students are on campus. This allows them to see their efforts realized in a completed issue. Also, holding some articles until the fall helps to smooth the editorial work flow and give the new editorial staff immediate opportunities to review articles when they return from summer break.

\section{UNDERGRADUATE CONFERENCES}

Student presentation at research conferences is another co-curricular activity that supports departmental curricular objectives and helps students to master Hansen's six proficiencies. Conference presentations also help students develop oral communication skills and confidence in sharing their research results. Student presenters also benefit from the critical feedback from discussants and attendees.

We encourage Illinois Wesleyan University senior economic majors to present their research at conferences. For example, all seniors are required to present their senior seminar research paper to at least one on-campus forum. We also encourage students who are pursuing research honors to consider presenting at an off-campus conference.

The last days of our senior seminar class in the fall are reserved for formal presentations by all seminar participants. In addition, many students choose to present at the campus wide undergraduate John Wesley Powell Research Conference. The conference is appropriately named after the well known explorer and founder of the National Geographic Society who taught for a short time at Illinois Wesleyan University. At the conference, students can choose to present their research as an oral presentation or as a poster presentation. The conference is particularly popular among the students who work on year long research honors projects under the supervision of faculty committees.

Conferences like this are a great way to recognize student research and provide opportunities for students to present to a wider audience. In the process, students build confidence and improve their formal presentation skills. Conference presentations also peak students' interest in research and are likely to increase the desire of many to pursue graduate school.

Departments that do not have access to university-wide undergraduate conferences should consider developing some sort of a forum for student presentations. Perhaps a mini-conference could be sponsored by the local chapter of the national economics honorary, Omicron Delta Epsilon, or the department's economic club. If a 
student club can't take ownership over the conference, the department might consider organizing a research conference.

We also encourage students to present at professional meetings. There are undergraduate sessions at the Missouri Valley Economic Association meetings in the fall, and sessions at the Midwest Economic Association and Eastern Economic Association meetings in the spring. The undergraduate journal Issues in Political Economy sponsors the undergraduate sessions at the Eastern Economic Association meetings. This initiative benefits students by linking two beneficial co-curricular activities, student publication and student presentation of research.

Off-campus conference presentations are expensive. Fortunately, Illinois Wesleyan University has a budget to support student travel when the purpose is to present papers at conferences. Our students have taken advantage of this support to present at venues like the Midwest Economic Association meetings, the Missouri Valley Economic Association meetings, and the undergraduate Carroll Round International Economics Conference at Georgetown University. Students enjoy these experiences, and the interactions that they have with other students and professional economists at off-campus conferences probably peaks their interest in research and provides indirect encouragement to pursue graduate studies.

\section{CONCLUSION}

From our experience at Illinois Wesleyan University, we have learned several things that might be of some use to other departments. First, a good capstone experience must be oriented toward increasing student proficiencies and this process must start before students enter their senior capstone course. Capstone experiences are best when there is enough depth in the major program to prepare students with the theoretical and empirical foundation to do original research. Ideally, they will also have taken several courses that require writing and working with the literature prior to their senior year.

Second, the capstone course should be an integrative experience where students systematically demonstrate all of Hansen's proficiencies. They should be free to choose their own research topic, but should be guided through the research project in stages. Also, they should get frequent feedback and have the opportunity to improve their skills through revision of drafts.

Third, providing incentives for good research through student edited publications and undergraduate conferences are excellent complements to a capstone senior seminar experience. These co-curricular activities extend active learning beyond the capstone seminar.

While there are many strategies for introducing undergraduate publication and conference presentation into an economics program, a phased approach may be the most practical. Perhaps publication and presentation activities could be gradually introduced as activities sponsored by already existing organizations such as Omicron Delta Epsilon chapters or academic clubs. This approach gives students some real "ownership" over the activities and an incentive to participate. A logical strategy would be to start with small manageable activities and to progress year by year in a systematic manner. For example, the first year might involve taking a few students to participate in a conference and encouraging one or two students to submit papers to undergraduate journals. The second year might involve setting up a departmental website that posts a few of the better senior seminar papers that are competitively selected by student editors. This exercise would provide incentives for students to do quality work and introduce them in a rather informal way to peer review. Also, during the second year, the department might sponsor a mini conference where students present their research to peers and faculty members. During the third year, the web site might be transformed into a full scale in-house journal with editorial policies, a student editorial board, and feature stories about the department and alumni. Finally, during the fourth or fifth year, an undergraduate journal could be set up that solicits articles from students at other universities.

Faculty advice will be required at every step, but a slow systematic approach will allow students to assume an important role in creating the co-curricular activities. As policies are implemented and students learn their editorial duties, the time commitment of faculty advisors will decrease, and departments will discover, as we did at Illinois Wesleyan University, that student involvement in journal publication and academic conferences is a very nice complement to any curriculum that emphasizes writing and depth. 


\section{APPENDIX A}

\section{Standard Questions For Analyzing Sample Research Articles}

1. Describe briefly the research problem addressed in this paper. Is the research problem clear? Is it an important research problem? (e.g., does it deal with an important issue or does it expand the literature in some way?)

2. Describe briefly the theoretical framework used in the paper. Is the theory relevant in the context of the research problem? Is the theory presented clearly?

3. Discuss one of the principle hypotheses generated by the theory. Does the hypothesis follow logically from the theory? Does it address the research problem?

4. Identify the research design used to test the hypothesis with particular attention on the empirical model and the data base. Is the research design appropriate for testing the research hypotheses?

5. Identify the most important finding of the study. Does the author discuss this finding in the context of the research problem developed early in the paper?

6. Identify the most important policy implications developed in the paper if there are any. Do the policy implications flow logically from the analysis? 


\section{APPENDIX B}

\section{Evaluation Form}

Author's Name

\section{Senior Project (ECON 401)}

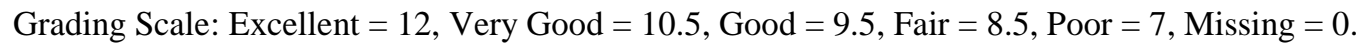

\section{Development of the Research Problem}

a) Purpose of the project is made clear in the introduction.

b) Background of the problem is fully developed.

c) Paper shows a mastery of the complexities of the topic.

\section{Treatment of Related Literature}

a) Related literature has been reviewed.

b) It is clear how the literature relates to the project.

c) Internal documentation of sources is thorough and consistent.

\section{Development of the Underlying Theory}

a) Theoretical model is fully developed.

b) Theory is relevant in the context of the research problem.

c) Research hypotheses follow logically from the theory.

\section{Empirical Research Design}

a) Research design developed to test hypotheses is presented clearly.

b) Data base is presented clearly and is appropriate.

c) Empirical model is described clearly and is appropriate to test hypotheses.

\section{Results}

a) Results are presented clearly.

b) Paper relates results to the research hypotheses.

c) Results are discussed in the context of related literature.

\section{Conclusions}

a) Major conclusions are clearly stated.

b) Conclusions are related to findings in related literature.

c) Policy implications are discussed and are consistent with conclusions.

\section{Style and Grammar}

a) Grammatical correctness.

b) Paragraph unity.

c) Transitions.

d) Visual Effects such as graphs and tables.

e) Consistency of Style.

Overall Effect: (24 possible)

Total: 


\section{APPENDIX C}

\section{Article Evaluation Form (UER)}

Please evaluate the article based on the following criteria, using a 5 point scale, where " 5 " is excellent and " 1 " is poor.

1. Is concerned with an important research problem.

2. Describes the research problem clearly and persuasively.

3. Uses a theoretical framework that is appropriate to the research problem.

4. Provides adequate supporting arguments, evidence, examples, and details.

5. Relates the principle findings back to the research problem.

6. Draws policy implications (if any) from the principle findings.

7. Uses appropriate research design and data (if applicable).

8. Is well organized and unified.

9. Uses appropriate, direct language.

10. Correctly acknowledges and documents sources.

11. Maintains a level of excellence throughout.

12. Shows originality and creativity in realizing (1) through (11).

13. Overall evaluation of the article.

Average Score:

Recommendation:

Accept Accept Subject to Minor Revisions

Decline

Comments (especially if recommended to decline):

\section{REFERENCES}

1. Carlson, J. Lon; Chizmar, John F.; Seeborg, Michael C.; and Walbert, Mark S. Using Undergraduate Journals and Peer Pressure to Improve Undergraduate Writing in Economics, 1998, The Journal of Economics, 24(2), pp. 77-86.

2. Hansen, W. Lee. Expected Proficiencies for Undergraduate Economics Majors, Journal of Economic Education, Summer 2001, 32(3), pp. 231-242.

3. Hansen, W. Lee. Integrating the Practice of Writing into Economics Instruction, in William E. Becker and Michael Watts, eds., Teaching Economics to Undergraduates: Alternatives to Chalk and Talk. Cheltenham, UK: Edward Elgar Publishing Limited, 1998, pp. 79-118.

4. Hansen, W. Lee. What Knowledge is Most worth Knowing for Economics Majors? American Economic Review, May 1986, 76(2), pp. 377-403.

5. Park Place Economist, Illinois Wesleyan University, <http://www2.iwu.edu/economics/PPE.shtml>, 2007.

6. Saunders, Phillip and Walstad, William B., eds. Teaching Undergraduate Economics: A Handbook for Instructors. New York: Irwin/McGraw Hill, 1998.

7. Siegfried, John J., Principles for a Successful Undergradute Economics Honors Program, The Journal of Economic Education, Spring 2001, 32(2), pp. 169-177.

8. $\quad$ Siegfried, John J.; Bartlett, Robin L.; Hansen, W. Lee; Kelley, Allen C.; McCloskey, Donald N.; and Tietenberg, Thomas H. The Status and Prospects of the Economics Major, The Journal of Economic Education, Summer 1991, 22(3), pp. 197-224.

9. Undergraduate Economic Review, Illinois Wesleyan University, < http://titan.iwu.edu/ econ/uer/> , 2007. 
NOTES 